\title{
Fuzzy Logic-Based Models of Transport Aircraft in Avoidance of Runway Excursion
}

\author{
Ray chung Chang ${ }^{*}$ \\ Dept. of Aviation Mechanical Engine., China University of Science and Technology, Hen-Shan (312), Taiwan \\ ${ }^{*}$ Corresponding author
}

\begin{abstract}
The flight dynamic equations in mathematics for aircraft response to the crosswind effects during the landing are highly non-linear partial differential equations. The main objective of this paper is to present fuzzy-logic modeling (FLM) technique to establish flight control models with the function of nonlinear dynamic inversion based on the datasets from the flight data recorder (FDR) for the purpose to solve the mathematical problems in engineering and safety problems in aviation community. A twin-jet transport with the runway excursion event due to crosswind effects during the landing will be the study case. The non-linear multi-dimensional numerical analysis technique to be used to analyze the causes of this flight event, emphasis to be placed on finding observable parameters for pilots to make appropriate actions are presented in this paper.
\end{abstract}

Keywords-internal functions; membership function; fuzzy-logic modeling (FLM); flight data recorder (FDR)

\section{INTRODUCTION}

The crosswind is the type of wind field with varying magnitude and/or direction as encountered by an aircraft. The flight dynamic equations in mathematics for aircraft response to the crosswind effects are nonlinear and unsteady. Landing in crosswind effects has been a safety issue for all types of airplanes. The current aircraft design practice and certification account only for constant crosswind. These events are now known as mainly caused, either directly or indirectly, by crosswind associated with dynamic ground effect. Although pilot training has been again and again emphasized, unfortunately existing training simulators for landing operation in crosswind effects have serious shortcomings and may lead to negative training. The latter implies the possibility that when pilots apply what are learned in simulators, the situation may get worse as pointed out by NASA researchers. A key issue in the shortcomings is the aerodynamic database in tabulated form, which is not capable of accounting for these crosswind effects. It should be emphasized that these crosswind effects can also be induced by aircraft motion, not just by atmospheric disturbances.

A twin-engine transport aircraft ran off the runway after touchdown due to crosswind encountered [1], the fuzzy-logic modeling (FLM) technique was employed to establish unsteady aerodynamic models by using the flight data from flight data recorder (FDR). The fuzzy-logic aerodynamic models were demonstrated to exhibit directional instability, unstable yaw damping, and loss of control effectiveness due to varying crosswind in the final several seconds in flare [1]. Although the fuzzy-logic aerodynamic models have robustness and nonlinear interpolation capability in predicting the degradation in stability and control characteristics [2], it can't provide the improved control strategy in avoidance of runway excursion. In avoidance of runway excursion event due to crosswind effects, this paper presents FLM technique to establish flight control models with the function of nonlinear dynamic inversion based on the datasets from the flight data recorder (FDR). A runway excursion event due to crosswind effects during the landing for a twin-jet transport is a specific example in the present paper. Before touchdown, it appeared that the flight was normal without having excursion possibility. Excursion may occur in crosswind effects if the rudder control is not appropriately applied. Appropriate application of rudder control will be demonstrated in the present

\section{Flight CONTROL MODEL}

Since the flight control models are established by using flight data, modeling technique is important and need to be carefully considered. First of all, those data are filtered through compatibility analysis [2] to satisfy the kinematic equations to remove measurement noises and biases.

Modeling procedures start from setting up numerical relations between the input (i.e. flight variables) and output (i.e. flight operations or aircraft response). In order to obtain continuous variations of predicted results, the present paper uses internal functions, instead of fuzzy sets, to generate the output of the model [3].

System identification in the present study includes two tasks: one is the model structure identification, and the other one is to identify the parameters that represent their corresponding model structures. The present modeling method was first developed by Takagi \& Sugeno in 1985 [4], and later in 1995, Tan \& Xie [5] applied the theory to simulate microelectronic processes with very good accuracy. The present study is based on the modeling technique suggested by Tan \& Xie. This technique was first applied to aviation technology in 1997 and later to flight data [6]. An application of this modeling technique to examine aeroelastic effects of a transport aircraft was presented in [7]. A detailed description of the fuzzy-logic algorithm is available in [2] and is summarized in Section 2.2 of the present paper.

A preprocessor is needed to re-arrange the flight variables in the dataset, and interpolate the variables if necessary by a monotone cubic spline. Traditional simulator database cannot exhibit unsteady aerodynamic effects in accident events in general, and therefore not suitable for training for recovery 
techniques. The runway excursion problem of the present study will be considered. The following numerical models based on FDR data in landing operation with dynamic ground effect may be generated:

$$
\delta_{r}=f\left(\alpha, \theta, \phi, \phi, \psi \&, V_{c a s}, \delta_{f}, a_{y}, V_{c r w}, V_{t l w}, h_{r}, V_{d}\right)
$$

where the parameter on left hand side of Eq. (2.19) represents the rudder angle $(\delta r)$ and flight variables on right hand side represent angle of attack $(\alpha)$, pitch angle $(\theta)$, roll angle $(\phi)$, time rate of roll angle $\left(\phi^{\delta}\right)$, time rate of heading angle $\left({ }^{\&}\right)$, calibrated airspeed $\left(V_{\text {cas }}\right)$, flap angle $(\delta \mathrm{f})$, lateral acceleration (ay), crosswind speed (Vcrw), tailwind speed (Vtlw), radar altitude (hr), and descent speed (Vd).

To develop flight control models, one or more dynamic variables (on the right-hand-sides of the above expressions) are chosen as the enabling variables to achieve the desired dynamics. In the present case, the time rate of yaw angle is to be changed, because it is directly related to rudder. However, associated with its change, lateral acceleration (ay), and time rate of roll angle $\left(\phi^{\&}\right)$ would be changed. Therefore, the following two sub-models are needed:

$$
\begin{aligned}
& a_{y}=f_{1}\left(\alpha, \theta, \phi, \psi \& V_{c a s}, \delta_{f}, V_{c r w}, V_{t l w}, h_{r}, V_{d}\right) \\
& \&=f_{2}\left(\alpha, \theta, \phi, \psi \& V_{c a s}, \delta_{f}, a_{y}, V_{c r w}, V_{t l w}, h_{r}, V_{d}\right)
\end{aligned}
$$

\section{NUMERICAL RESULTS AND DISCUSSIONS}

\section{A. Flight Data}

In the present study, a runway excursion due to crosswind effects during the landing for a twin-jet transport is a specific example to analyze the causes of this flight event and to make appropriate actions as the improved control strategy in avoidance of runway excursion event. The datasets of this transport used for the modeling are extracted from FDR of this flight event.

The main aircraft geometric and inertial characteristics are taken to be:

$$
\begin{aligned}
& \mathrm{W}=533,790 \mathrm{~N}(120,000 \mathrm{lb}) \\
& \mathrm{S}=112.32 \mathrm{~m} 2(1209 \mathrm{ft} 2), \bar{C}=3,41 \mathrm{~m}(11.2 \mathrm{ft}), \\
& \mathrm{b}=32,89 \mathrm{~m}(107.9 \mathrm{ft}) \\
& \mathrm{Ixx}=2,507,963 \mathrm{~kg} \cdot \mathrm{m} 2(1,849,530 \text { slugs-ft }), \\
& \text { Iyy }=6,402,517 \mathrm{~kg} \cdot \mathrm{m} 2(4,721,620 \text { slugs-ft2 }) \\
& \text { Izz }=8,569,733 \mathrm{~kg} \cdot \mathrm{m} 2(6,319,862 \text { slugs-ft2 }), \\
& \mathrm{Ixz}=141,940 \mathrm{~kg} \cdot \mathrm{m} 2(104,676 \text { slugs-ft } 2)
\end{aligned}
$$

The necessary data in the FDR to determine the flight operations for this transport is time $(\mathrm{t})$, angle of attack $(\alpha)$, pitch angle $(\theta)$, roll angle $\left({ }^{\phi}\right)$, heading angle $(\psi)$, calibrated airspeed ( $\left.V_{c a s}\right)$, flap angle $(\delta f)$, lateral acceleration (ay), crosswind speed (Vcrw), tailwind speed (Vtlw), radar altitude (hr), and descent speed (Vd). Since the lateral acceleration (ay) is a major flight varuable of the present study, this parameter is recorded in $4-\mathrm{Hz}$ resolution (i.e. 4 points per second), all other parameters are interpolated with a monotone cubic spline to the same sampling rate.

\section{B. Reconstruction of Flight Events}

In the present paper, a twin-jet transports is employed as the study case for runway excursion event. In order to reconstruct the flight condition of this event, the datasets in landing phase from $\mathrm{t}=45233$ to $45431 \mathrm{sec}$ are used for the modeling. Before touchdown, it appeared that the flight was normal without having excursion possibility due to the variations of crosswind speed are from 8 to $3 \mathrm{~m} / \mathrm{s}$ on the decrease, as shown in Figure 3.1 and the heading angles with small variations, as presented in Figure 3.2. However, after touchdown there was a strong $12 \mathrm{~m} / \mathrm{s}$ (21kts) gust toward the right at around $\mathrm{x}=200 \mathrm{~m}$, as shown in Figure 3.3. Note. Negative tailwind is headwind and the distance of runway $\mathrm{x}=0$ $\mathrm{m}$ is defined as the touchdown point. The positive gust reduces the heading angle, as it should be, but the heading angle immediately increases again, as presented in Figure 3.2. Positive increase in heading angle plus the positive drift angle should be the cause of runway excursion. The critical point of moving trajectory on the runway is at $\mathrm{x}=520 \mathrm{~m}$; the transport doesn't move back to the center line of the runway (i.e. $y=0$ $\mathrm{m})$. On the contrary, the transport moves toward the outside of the runway boundary at $\mathrm{x}=680 \mathrm{~m}$, as shown in Figure 3.4.

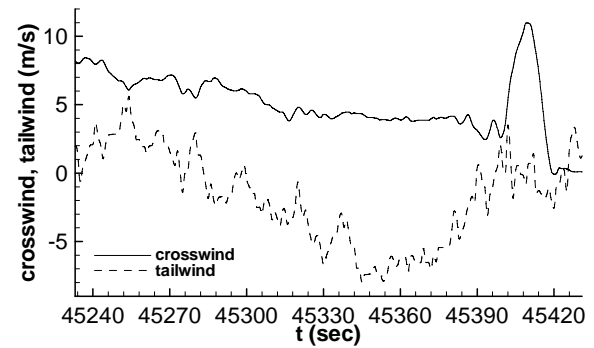

FIGURE I. TIME HISTORY OF WIND FIELD DURING LANDING

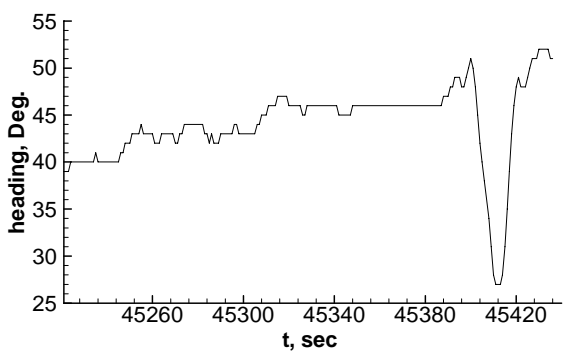

FIGURE II. TIME HISTORY OF HEADING ANGLES DURING LANDING 


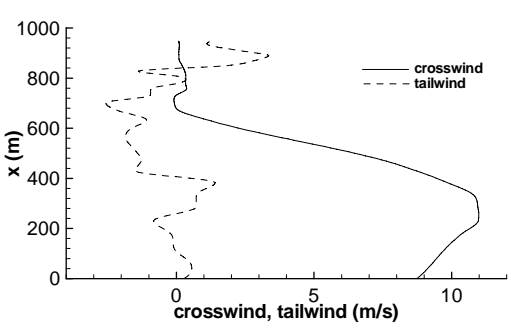

FIGURE III. TIME HISTORY OF WIND FIELD AFTER TOUCHDOWN

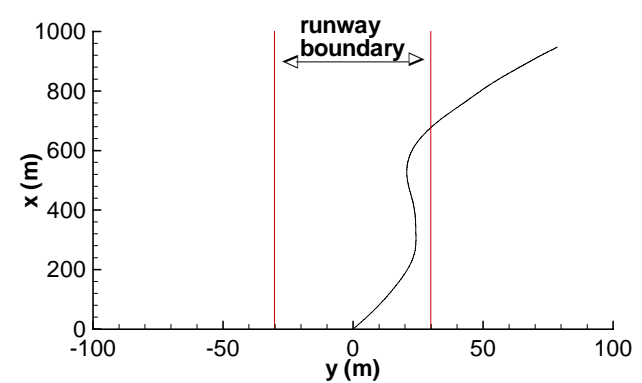

FIGURE IV. MOVING TRAJECTORY OF RUNWAY EXCURSION

EVENT

\section{Analysis of Model Predictions}

In the present study, the accuracy of the established rudder control model with two sub-models through FLM algorithm is estimated by the sum of squared errors (SSE) and the square of multiple correlation coefficients (R2). The predicted rudder angle ( $\delta$ r), lateral acceleration (ay), and time rate of roll angle $\left(\phi^{\&}\right)$ to compare with those of flight data in landing phase have a good agreement.

\section{Root Causes of Flight Event}

Initially, the aircraft was moving to the right because of positive drift angles (see later) after touchdown. So the rudder was deflected positively to generate negative time rate of heading angles, as presented in Figure 3.5 and Figure3.6 The transport aircraft encountered a strong gust with the speed of $12 \mathrm{~m} / \mathrm{s}$ toward the right after touchdown at around $\mathrm{x}=200 \mathrm{~m}$, as shown in Figure 3.3. The pilot quickly used the left rudder to move the transport aircraft to the left to correct the heading angles of aircraft. At around $\mathrm{x}=305 \mathrm{~m}$ in Figure 3.3, a large positive crosswind occurred and this was countered by a negative rudder (right pedal) with some delay (by about $4 \mathrm{sec}$.), as shown in Figure 3.5. This makes the time rate of heading angles more positive so that the aircraft moved to the right side continuously, as presented in Figure 3.6. The rudder operations in heading angle corrections were not proper due to the wind direction suddenly change from the tailwind to headwind at $\mathrm{x}=396 \mathrm{~m}$. The critical point of runway excursion was at $\mathrm{x}=520 \mathrm{~m}$ and toward the outside of the runway boundary at $\mathrm{x}=680 \mathrm{~m}$, as shown in Figure 3.4.

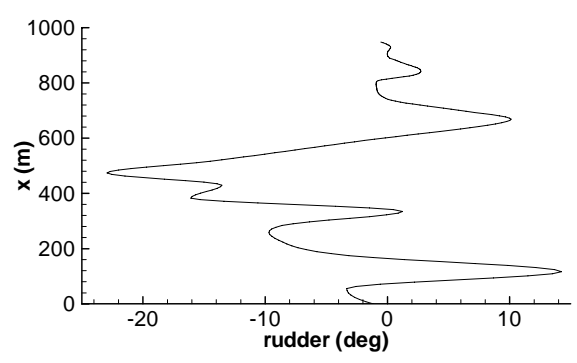

\section{FIGURE V. TIME HISTORY OF RUDDER OPERATIONS AFTER} TOUCHDOWN

Note that a positive crosswind would generate a positive side force and reduce the heading angle. Therefore, the increase in heading angle should be caused by the large negative rudder. A negative rudder would produce negative side force on the vertical tail and positive time rate of heading angle. Positive increase in time rate of heading angle plus the wind direction suddenly change from the tailwind to headwind should be the causes of runway excursion event.

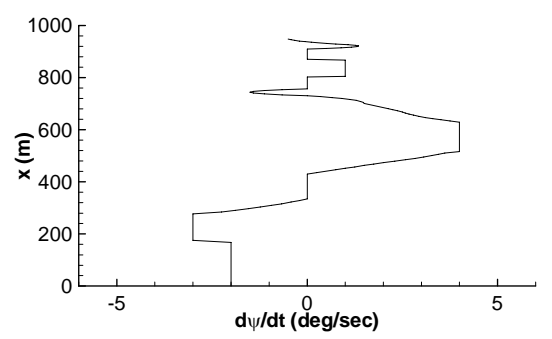

FIGURE VI. TIME HISTORY OF TIME RATE OF HEADING ANGLES AFTER TOUCHDOWN

\section{E. Improved Control Strategy}

In a positive crosswind, the drift angle is positive and the airplane will move to the right side. To determine if excursion can be avoided: A small $(\mathrm{d} \psi / \mathrm{dt})$ is imposed for positive crosswind. The original and improved time rates of heading angles are shown in Figure 3.7. The solid line represents the improved time rate of heading angles. To slow down the motion to the right side by making the time rate of heading angles slightly more negative (adding $-0.25 \mathrm{deg} / \mathrm{sec}$ ) until passing through the region of maximum positive time rate of heading angles (around $\mathrm{x}=520 \mathrm{~m}$ ) or the ground speed vector is along the runway, after which the time rate of heading angles should be reduced to zero gradually. After the maximum positive time rate of heading angles period, try to damp out the positive time rate of heading angles. The final results indicate that excursion can indeed be avoided. 


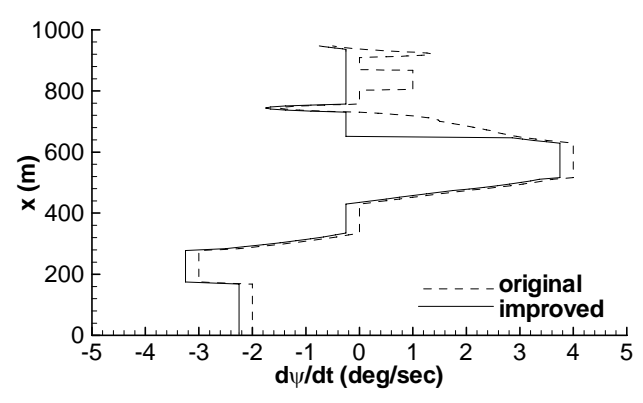

FIGURE VII. ORIGINAL AND IMPROVED TIME RATES OF HEADING ANGLES AFTER TOUCHDOWN

The original and improved drift angle (drift), change in heading angle $(\Delta \psi)$, and rudder angle ( $\delta \mathrm{r})$ are shown in Figure 3.8 and Figure 3.9, respectively. The over-all control strategy is to make the sum of drift angle and change in heading angle $(\Delta \psi)$ after touchdown to be as small as possible. The most important part in control is not to allow $\Delta \psi$ to be more positive in a positive crosswind (from left to right). If the visibility is good enough, and the crosswind direction is known, initially a pilot can just use the left pedal in a positive crosswind and right pedal in a negative crosswind to make the adjustment such that the rudder deflection not to exceed the limits. In the example presented, the rudder limits are specified as 30.0 and -30.0 degrees. The most important parameter to observe is the drift angle. If it is positive, the airplane is moving to the right relative to flight direction. A left rudder pedal should be applied to generate negative time rates of heading angles until (drift angle $+\Delta \psi$ ) is nearly zero or the airplane is moving in the desired direction. If the drift angle is around $10 \mathrm{deg}$., the starting point of application may be at the touchdown point. If the drift angle is around 20 deg., the starting point of application should be moved forward to radio altitude (hr) = $50 \mathrm{ft}$.

Another important phenomenon is the oscillating negative side acceleration in positive crosswind. Normally, positive crosswind would produce positive side acceleration. However, when the crosswind is large enough, the aerodynamic performance of the vertical tail could be changed. The crosswind will blow the aircraft wake, including the engine exhaust, toward the vertical tail on the windward side. In addition, the airstream toward the vertical tail is always turbulent. Even if the crosswind limit may not be exceeded, the crosswind limit in design is established with respect to the available control power of aileron, not rudder. The crosswind limit for the rudder may be lower. A successful control strategy in rudder pedal is to apply unsteady control deflections such as those displayed at $\mathrm{x}=200 \mathrm{~m}$ to $540 \mathrm{~m}$ and then at $x=640 \mathrm{~m}$ to $960 \mathrm{~m}$ on the runway in Figure 3.9.

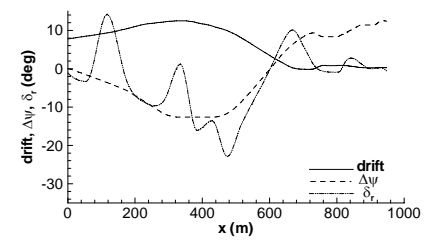

FIGURE VIII. ORIGINAL DRIFT ANGLE, CHANGE IN HEADING ANGLE, AND RUDDER ANGLE AFTER TOUCHDOWN

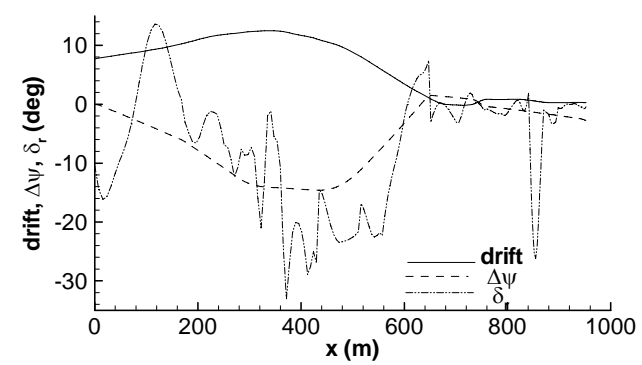

FIGURE IX. IMPROVED DRIFT ANGLE, CHANGE IN HEADING ANGLE, AND RUDDER ANGLE AFTER TOUCHDOWN

\section{CONCLUDING REMARKS}

The main objective in this paper was to present the development of flight control models based on FLM method and the resulting models having the capability to solve the mathematical problems in engineering and safety problems in aviation community. A twin-jet transport with the runway excursion $f$ event due to crosswind effects during the landing was an illustration in this paper. The numerical results and discussions of application to flight control models were concluded as follows:

1) The correlation of the flight data points were estimated and improved by monitoring a multi-variable relation in the modeling process.

2) The predicted results presented that the final models could examine the root causes of runway excursion event through flight operations with response to the crosswind effects.

3) The fuzzy logic-based flight control sub-models were shown to have the function of nonlinear dynamic inversion and to provide the improved control strategy in avoidance of runway excursion event.

The analytical results could provide the mitigation concepts and promote the understanding of dynamic responses of the transport aircraft with crosswind effects.

\section{ACKNOWLEDGMENTS}

This research project is sponsored by a grant, MOST 1042221-E-157-003-, from Ministry of Science and Technology (MOST), Taiwan. The accomplishment in this project is part of the requirements set by the Aviation Safety Council (ASC), Taiwan.

\section{REFERENCES}

[1] C. T. Weng, C. S. Ho, C. E. Lan, and M. Guan, "Aerodynamic Analysis of a Jet Transport in Windshear Encounter during Landing," AIAA Journal of Aircraft, vol. 43, no. 2, pp. 419-427, 2006.

[2] C. E. Lan and R. C. Chang, Chapter 7 Fuzzy-Logic Analysis of the FDR Data of a Transport Aircraft in Atmospheric Turbulence, Part 2, Fuzzy Logic-Emerging Technologies and Applications, InTech - 51000, 2012, ISBN 978-953-51-0337-0, Rijeka, Croatia.

[3] J. Montero, D. Gómez, and H. Bustince, "On the Relevance of Some Families of Fuzzy Sets," Fuzzy Sets and Systems, Vol. 158, No. 22, 16, 2007, pp. 2429-2442.

[4] T. Takagi and M. Sugeno, "Fuzzy Identifications of Systems and Its Applications to Modeling and Control," IEEE Transactions on Systems, Man and Cybernetics, Vol. SMC-15, No. 1, 1985, pp. 116-132.

[5] J. Tan, H. Xie, and Y. C. Lee, "Efficient establishment of a fuzzy logic 
model for process modeling and control," IEEE Transactions on Semiconductor Manufacturing, Vol. 8, No. 1, 1995, pp. 50-61.

[6] R. C. Chang, C. E. Ye, C. E. Lan, and W. L. Guan, "Flying Qualities for a Twin-Jet Transport in Severe Atmospheric Turbulence," AIAA Journal of Aircraft, Vol. 46, No. 5, Sept.-Oct. 2009, pp. 1673-1680.

[7] R. C. Chang and C. E. Lan, "Structural Health Monitoring of Transport Aircraft with Fuzzy Logic Modeling," Mathematical Problems in Engineering, Volume 2013 (2013), Article ID640852, 11 pages. 